\title{
Personal and environmental predictors of academics`work-to-family enrichment at Research Universities
}

\begin{abstract}
This paper aims to discover predictors of academics' work-to-family enrichment at Malaysian Research Universities. The underlying theoretical foundations of this study are the work-family enrichment theory by Greenhaus and Powell and the model of primary antecedents, consequences, and moderators of facilitation by Wayne, Grzywacz, Carlson, and Kacmar. The sample includes 295 academics from three Malaysian Research Universities, and data were gathered via online and offline surveys. This study found that all the selected personal factors (i.e. extraversion, core self-evaluation, overall health), and environmental factors (i.e. social support, job autonomy, supportive work-family culture) were significantly related to work-to-family enrichment among the academics. In addition, extraversion and social support were the best predictors of academics' work-to-family enrichment. Conclusion and implications for theory and practice are discussed in the paper.
\end{abstract}

Keyword: Work-family enrichment; Personal factors; Environmental factors; Research universities; Social support; Extraversion 